\title{
Anti-leukemic activity of a four-plant mixture in a leukemic rat model
}

\author{
Mai M. Kabeel, Ahmed M. Ghoneim* and Seham E. Mansy
}

\begin{abstract}
Background: Leukemia is a malignant blood disease caused by the overproduction of a large number of immature blood cells that enter the peripheral blood. Because of the side effects associating the chemotherapy of leukemia, the identification of medicinal herbs, therefore, remains to be an attractive goal to treat leukemia.

Results: In this study, leukemia was experimentally induced in rats by 7, 12-dimethyl benza[a]anthracene (DMBA) and rats were treated with a water extract of a four-plant (Arctium lappa, Ulmus rubra, Rumex acetosella, and Rheum palmatum) mixture. Application of this four-plant mixture extract successfully recovered weight loss and restored the normal total WBC, lymphocyte and neutrophil counts in a leukemia rat model compared to either the DMSOtreated rats or the leukemic rats before applying the plant mixture. Moreover, this plant mixture decreased the percentage of blasts by two thirds in leukemic rats. By quantitative real-time PCR, sphingosine-1-phosphate receptor-1 mRNA expression in lymphocytes was downregulated in leukemic rats, and this downregulation was significantly alleviated by treating the leukemic rats with the plant mixture.
\end{abstract}

Conclusion: This study investigates, for the first time, the effect of this plant mixture on a chemically induced leukemia rat model. Results further support previous reports about the anti-carcinogenic effect of this plant mixture and highlights the possibility of its use in leukemia treatment to avoid the negative side effects of the usual therapy.

Keywords: Leukemia, DMBA, Medicinal herbs, Cytotoxicity, Sphingosine-1-phosphate receptor 1, Gene expression

\section{Background}

Leukemia is a malignant disease of blood-forming tissues causing the overproduction of immature blood cells that enter the blood stream (Azher \& Shiggaon, 2013). It is the ninth most common cancer in men and the 12th in women (Quinn, Babb, Brock, Kirby, \& Jones, 2001). Leukemia can be classified basically as lymphoid or myeloid, according to the cell lineage, and as acute or chronic, according to the evolution of the disease (Love, 1936; Javed et al., 2012). Its etiologic factors include genetic alteration, environmental factors, smoking, alcohol consumption, chemicals, viruses, ionizing radiation, and immune deficiency (Kinane, 1999; Eden, 2010). This disease is usually treated by chemotherapy, combined with radiation and allogeneic hematopoietic stem cell transplantation (HSCT) (Seibel, 2008). Chemotherapy is one of therapeutic options for cancer, but it has severe side effects and dose-limiting toxicity (Camp-Sorrell, 2000). A lot of patients prefer

\footnotetext{
* Correspondence: am_ghoneim@du.edu.eg

Zoology Department, Faculty of Science, Damietta University, New Damietta, P.O. 34517, Damietta, Egypt
}

medicinal herbs that are safe in contrast to chemotherapy and radiotherapy (Mankaran, Dinesh, Deepak, \& Gurmeet, 2013). Several types of herbs and fruits and their compounds were reported to inhibit carcinogen formation, block carcinogen interaction, and suppress tumor progression (e.g., ginseng root, garlic, Achillea fragrantissima) (Abdullah, Kandil, Elkadi, \& Carter, 1988; Alenad, AlJaber, Krishnaswamy, Yakout, Al-Daghri, et al., 2013).

In Canadian traditional medicine, the burdock root (Arctium lappa), the inner bark of slippery elm (Ulmus fulva or Ulmus rubra), sheep sorrel (Rumex acetosella), and rhubarb (Rheum palmatum) have been reported to have anticancer activity (Minyi, 1992). A widely used herbal extract formulation (Essiac ${ }^{\circ}$ ) has been commercially produced and it is widely used as a complementary and alternative medicine (CAM) by some cancer patients and survivors (Kulp et al., 2006). These four plants were reported to have hepatoprotective, antiinflammatory (A. lappa, $R$. palmatum), strong antioxidant and free radical scavenging (A. lappa), gastroprotective $(R$. palmatum, $U$. rubra), and anti-septic and anti-spasmodic 
(R. palmatum) activities (Bradley, 1992; Lin, Lin, Yang, Chuang, \& Ujiie, 1996; Duh, 1998; Tamayo, Richardson, Diamond, \& Skoda, 2000; Lin et al., 2002). A. lappa leaf extract ameliorated cadmium genotoxicity and the histopathological effects in the rat kidney at different doses (Al-Gebaly, 2017).

These plants were also used to treat diarrhea ( $U$. fulva or $U$. rubra; $R$. acetosella), skin inflammations ( $U$. fulva or $U$. rubra; $R$. acetosella; $R$. palmatum), viral infections, respiratory diseases ( $R$. acetosella), intestinal bleeding, pancreatitis, kidney diseases ( $R$. palmatum), convalescence, cough, and sore throat ( $U$. fulva or $U$. rubra) (Castleman, 1991; Bradley, 1992; Duke, 1997; Gescher, Hensel, Hafezi, Derksen, \& Kühn, 2011). A. lappa is used as diuretic, depurative, digestive stimulant, and anti-allergic (Soh et al., 2011; De Almeida et al., 2012). $R$. palmatum contains a natural anthraquinone called emodin that has been reported to inhibit the protein kinase CK2 (Yim, Lee, Lee, \& Lee, 1999) and to block cell division of Trypanosoma cruzi epimastigotes in vitro (De Lima et al., 2017).

Some studies have shown anti-carcinogenic effects for the Indian rhubarb extract, and aloe emodin, an anthraquinone present in rhubarb family, was shown to have both tumor inhibition and tumor initiation properties (Kupchan \& Karim, 1977; Masuda \& Ueno, 1984; Morita, Umeda, Masuda, \& Ueno, 1988).

Using cell line system, this plant mixture has been shown to effectively reduce hydroxyl radical up to $84 \%$, and superoxide radicals up to $82 \%$ at the $50 \%$ concentration of this mixture, and in addition, the mixture prevented hydroxyl radical-induced DNA damage and inhibited hydroxyl radical-induced lipid peroxidation up to $50 \%$ at the $50 \%$ mixture preparation concentration (Leonard et al., 2006).

Despite these studies and the diverse therapeutic effect of these plants (U. rubra, A. lappa, R. acetosella, and $R$. palmatum), no studies have investigated their antileukemic effect in vivo. Therefore, the present study was designed to explore whether the mixture of these four plants has anti-leukemic effects in a leukemic rat model.

To unravel the molecular mechanisms through which this plants' mixture could exert its effects, we evaluated the expression of sphingosine-1-phosphate receptor-1 (S1PR1). S1PR1 is one of five G protein-coupled receptors that bind to sphingosine-1-phosphate (S1P) with high affinity, and it is well known to be expressed in a wide variety of cell types and tissues, including immune cells and endothelial cells (Chae, Proia, \& Hla, 2004; Rivera \& Chun, 2006).

\section{Methods}

\section{Animals and plants}

Twenty-five male albino Wistar rats (weight range 65-100) were obtained from Helwan animal station,
Ministry of Health, Egypt, and housed in plastic cages under controlled temperature in the animal house in the Zoology Department, Faculty of Science, Damietta University, New Damietta, Egypt.

Burdock root (A. lappa), the inner bark of slippery elm (U. rubra), sheep sorrel ( $R$. acetosella), and rhubarb (R. palmatum) were obtained from Egyptian herbal market and prepared as follows: The burdock root $(A$. lappa) roots $(680 \mathrm{~g})$, slippery elm ( $U$. rubra) leaves $(120 \mathrm{~g})$, sheep sorrel $(R$. acetosella) aerial parts (455 g), and turkey rhubarb ( $R$. palmatum) root (30 g) (Leonard et al., 2006) were mixed together. In 11 of distilled water, $25 \mathrm{~g}$ aliquots of this mixture were boiled for $10 \mathrm{~min}$. The mixture was then left to cool for $4 \mathrm{~h}$ followed by another 5-min boil, stored overnight in a refrigerator, and used within a week of preparation (Leonard et al., 2006).

\section{Experimental design}

Experimental animals were divided into five groups of five rats each: Group (1) (untreated group): rats were given basal diet and water for 2 weeks. Group (2) (carrier group): rats were intravenously injected with DMSO biweekly for 6 weeks (four times). Group (3) (DMBA group): rats were intravenously injected with DMBA biweekly for 6 weeks (four times). Group (4) (DMBA + plant mixture group): rats were intravenously injected biweekly with DMBA for 6 weeks, after which blood was drawn from the caudal vein ("DMBA before plants" subgroup). This group was then treated with the water extract of the four mixed plants as a drink for 2 weeks ("DMBA with plants" subgroup). Group (5) (plant mixture group): rats were given the water extract of the four mixed plants as a drink for 2 weeks.

\section{Leukemia induction and assessment}

Leukemia was experimentally induced in rats by a series of intravenous injections of 7, 12-dimethyl benza[a]anthracene (DMBA) (Sigma). A $20 \mathrm{mg} / \mathrm{ml}$ emulsion was prepared in DMSO (supplemented with olive oil) and injected to 30-35-day-old rats; the initial dosage was $40 \mathrm{mg} / \mathrm{kg}$ body weight. The dose of the three subsequent injections was $30 \mathrm{mg} / \mathrm{kg}$ body weight with an interval of 2 weeks between the successive injections. Leukemia was evaluated by loss of weight, counting of peripheral blood leucocytes, and the presence of malignant blasts and atypical lymphocytes in the peripheral blood withdrawn from the tail.

\section{Growth performance and WBC count}

Rats were weighed every week for the whole period of the experiment. Weight gain was calculated after the last week, and then rats were killed by anesthesia and 
laparotomy. Blood was withdrawn from the heart by a syringe for analysis. Total WBCs were counted according to standard protocol using a hemocytometer after dilution and staining with Gentian violet. WBC differential count was performed according to the standard protocol by staining blood films with Leishman's stain and examining them with an oil lens.

\section{Quantitative real-time PCR for S1PR1}

Lymphocytes were isolated from the blood of three rats of each group ("untreated," "carrier," "DMBA," "plants after DMBA," and "plant mixture") using Lymphocyte Separation Medium (17-829E, Lonza) according to the manufacturer's instructions. Total RNA was extracted from the isolated lymphocytes using GeneJET RNA Purification Kit (\#K0731, Thermo Scientific). RNA was purified by DNase $\mathrm{I}$ and reverse transcribed using RevertAid $\mathrm{H}$ Minus First Strand cDNA Synthesis Kit (\#K1631, Thermo Scientific), according to the manufacturer's instructions. Quantitative real-time PCR for S1PR1 was performed using Maxima SYBR Green PCR Master Mix (\#K0251, Thermo Scientific) in 20- $\mu$ l reactions. S1PR1 cDNA was quantitated using the forward primer 5 ' - CCGCTTGAG CGAGGCTGCTG-3' and the reverse primer 5-CTATGA TATCATAGTTGCCATAGTC-3' (synthesized in Biolegio company, Netherlands). The reference gene ( $\beta$-actin) was detected using forward primer 5 '-CCTTCTACAAATGA GCTGCGT-3' and the reverse primer 5'-CCTGGATAG CAACGTACATG-3' (synthesized in Biolegio company, Netherlands). Reactions were loaded in an Mx3000P QPCR Systems (Stratagene). The thermal cycling conditions were $95^{\circ} \mathrm{C}$ for $10 \mathrm{~min}$, followed by 40 cycles of $95^{\circ} \mathrm{C}$ for $15 \mathrm{~s}, 60{ }^{\circ} \mathrm{C}$ for $15 \mathrm{~s}$, and $72{ }^{\circ} \mathrm{C}$ for $30 \mathrm{~s}$. Data were analyzed by the $\Delta \Delta \mathrm{Ct}$ method and S1PR1 expression fold changes were calculated.

\section{Statistical analysis}

All values in the figures and texts are expressed as arithmetic means \pm standard error of the mean (SEM). The statistical significance of differences for each parameter among the groups was evaluated by one-way analysis of variance (ANOVA) followed by Tukey's HSD analysis. $p$ values of $<0.05$ were considered statistically significant.

\section{Results}

\section{DMSO is asuitable carrier}

Dimethyl sulfoxide (DMSO) was chosen as a carrier to deliver 7, 12-dimethylbenz[a]anthracene (DMBA) to rats. To check whether DMSO has adverse effects on the rats, the "untreated" rat group was compared with the carrier "DMSO" rat group for different biological parameters (Figs. 1, 2, 3, 4, 5, 6, 7, and 8). There was no significant differences in weight gain $(p>0.05)$ (Fig. 1), total WBC count $(p>0.05)$ (Fig. 2), percentage of lymphocytes $(p>0.05)$ (Fig. 3), percentage of neutrophils $(p>0.05)$ (Fig. 4), percentage of blasts $(p>0.05)$ (Fig. 5), percentage of monocytes $(p>0.05)$ (Fig. 6), percentage of eosinophils $(p>0.05)$ (Fig. 7), and percentage of basophils $(p>0.05)$ (Fig. 8). These results validate the use of DMSO as a carrier in this study. Significance values for pairwise comparisons between all groups are shown in Table 1.

\section{DMBA induces leukemia in rats}

To test whether DMBA successfully induced leukemia in rats, "DMBA" rat group was compared with "carrier" rat group with respect to weight gain, total WBC count, percentage of lymphocytes, percentage of neutrophils, percentage of blasts, percentage of monocytes, percentage of eosinophils, and percentage of basophils (Figs. 1, 2, 3, 4, 5, 6,7 , and 8 ). In "DMBA" rat group, a significant reduction $(p<0.05)$ in the weight gain (Fig. 1), a significant increase

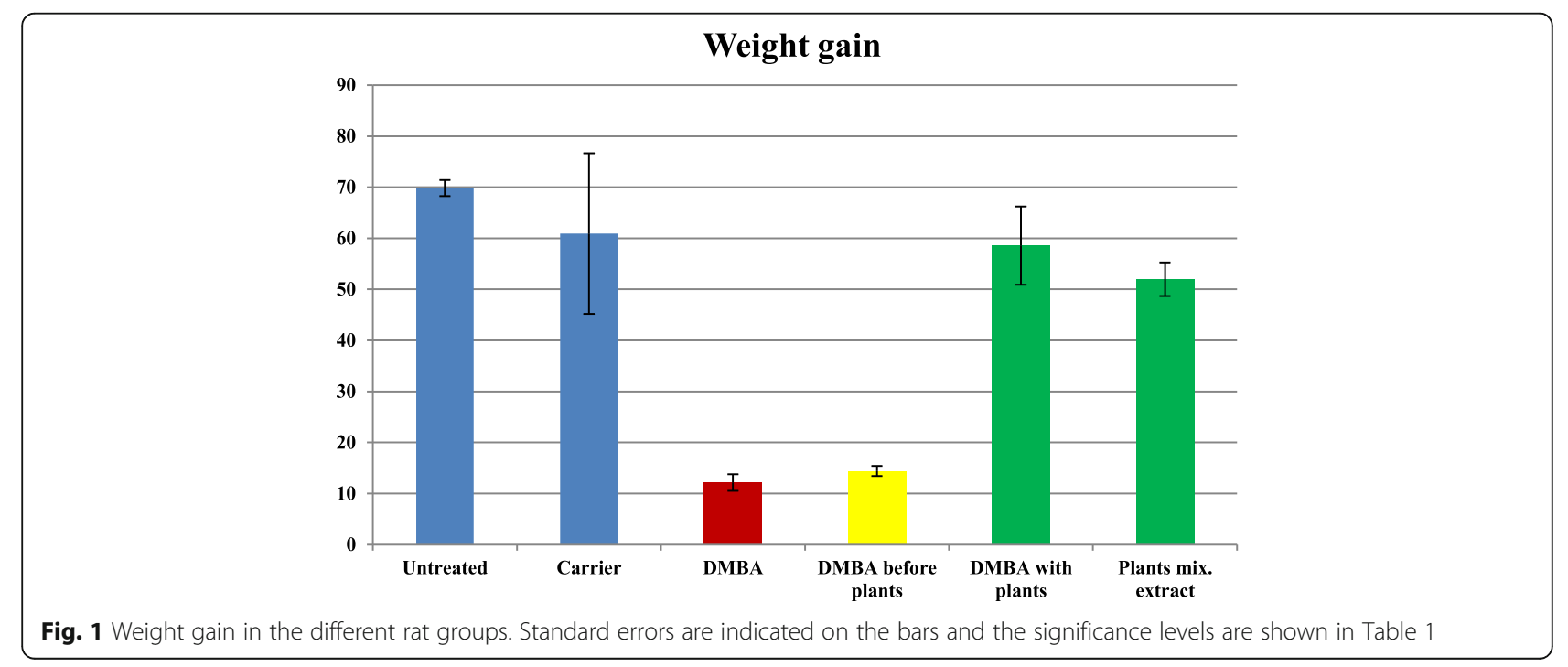




\section{Total WBCs count}

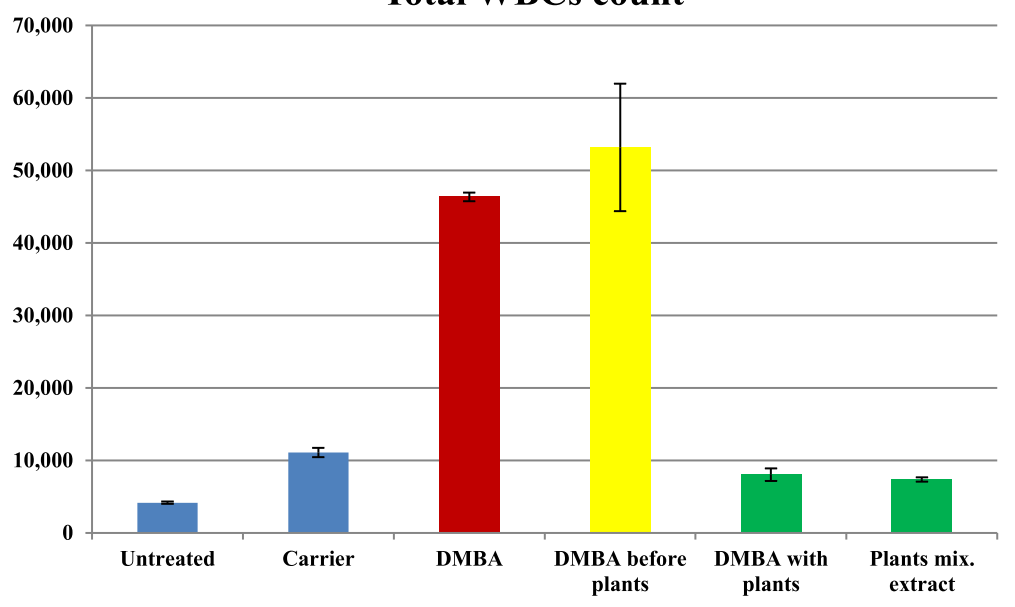

Fig. 2 Total WBC count in the different rat groups. Standard errors are indicated on the bars and the significance levels are shown in Table 1

$(p<0.05)$ in total WBC count (Fig. 2), a significant reduction $(p<0.05)$ in the percentage of lymphocytes (Fig. 3), a slight non-significant reduction $(p>0.05)$ in the percentage of neutrophils (Fig. 4), and a highly significant increase $(p<0.05)$ in the percentage of blasts were recorded (Fig. 5). No change was recorded in the percentage of monocytes $(p>0.05)$ (Fig. 6), percentage of eosinophils $(p>0.05)$ (Fig. 7), and percentage of basophils $(p>0.05)$ between "DMBA" and "carrier" rat groups (Fig. 8).

\section{The plant mixture extract alleviates leukemia in rats}

To investigate whether the plant mixture ( $U$. rubra, $A$. lappa, $R$. acetosella, and R. palmatum) extract can alleviate leukemia induced in rats, rats were treated with DMBA biweekly for 6 weeks followed by treatment with the plant mixture extract as a drink for 2 weeks. Compared to "carrier" rat group, there was a significant reduction $(p<0.05)$ in the weight gain in the "DMBA before plants" rat subgroup. After the application of plant mixture extract on the DMBA-treated rats, a non-significant difference $(p>0.05)$ in the weight gain between "DMBA with plants" rat subgroup and the "carrier" rat group was recorded (Fig. 1). This indicates weight recovery in the rats treated with plants. A significant increase $(p<0.05)$ in the total WBC count was recorded in the "DMBA before plants" rat subgroup compared to the "carrier" group (Fig. 2). After the application of plant mixture extract on the DMBA-treated rats, a non-significant difference $(p>0.05)$ in the total WBC count was recorded between the "DMBA with plants" rat subgroup and the "carrier" rat group, indicating restoration of the normal total WBC count in the rats treated with plant mixture extract (Fig. 2). Within the same group, a significant increase $(p<0.05)$ in the weight gain and a significant reduction $(p<0.05)$ in the total WBC count were recorded in the DMBA-treated rats after

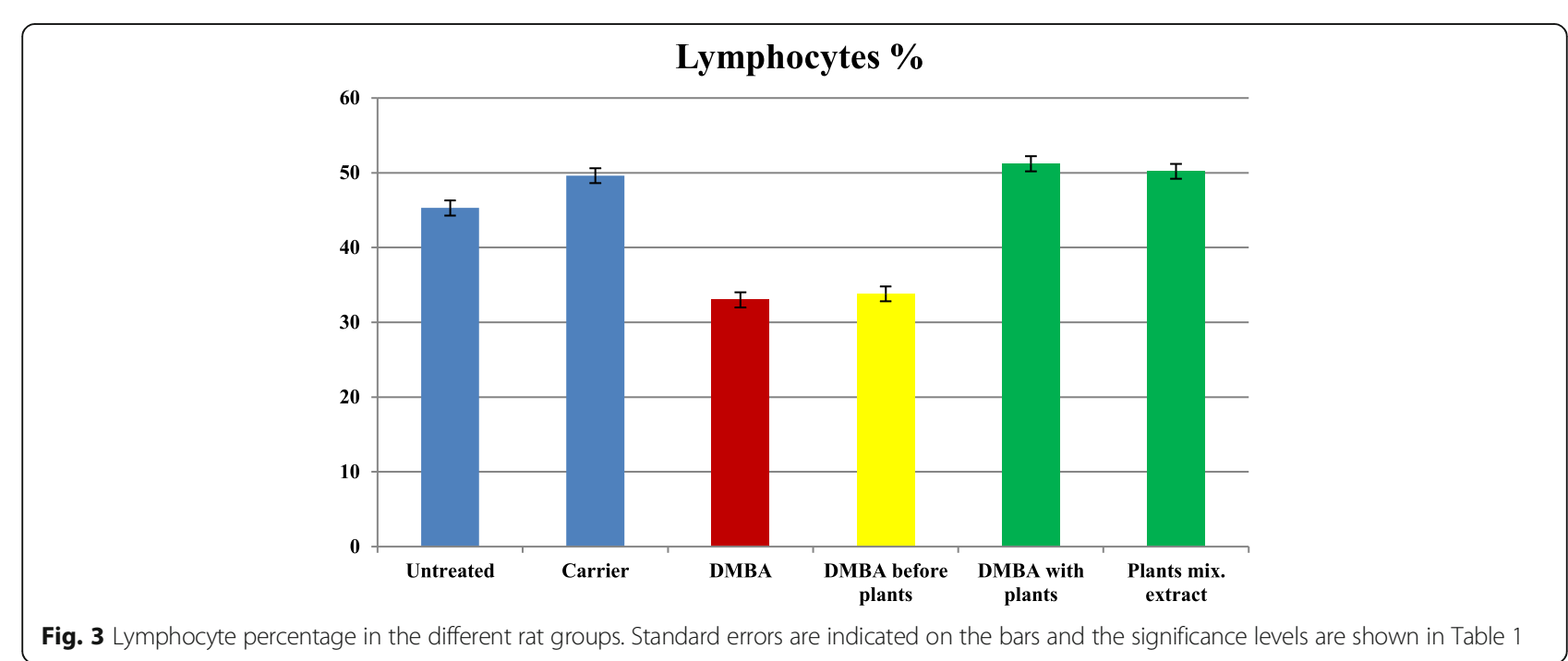




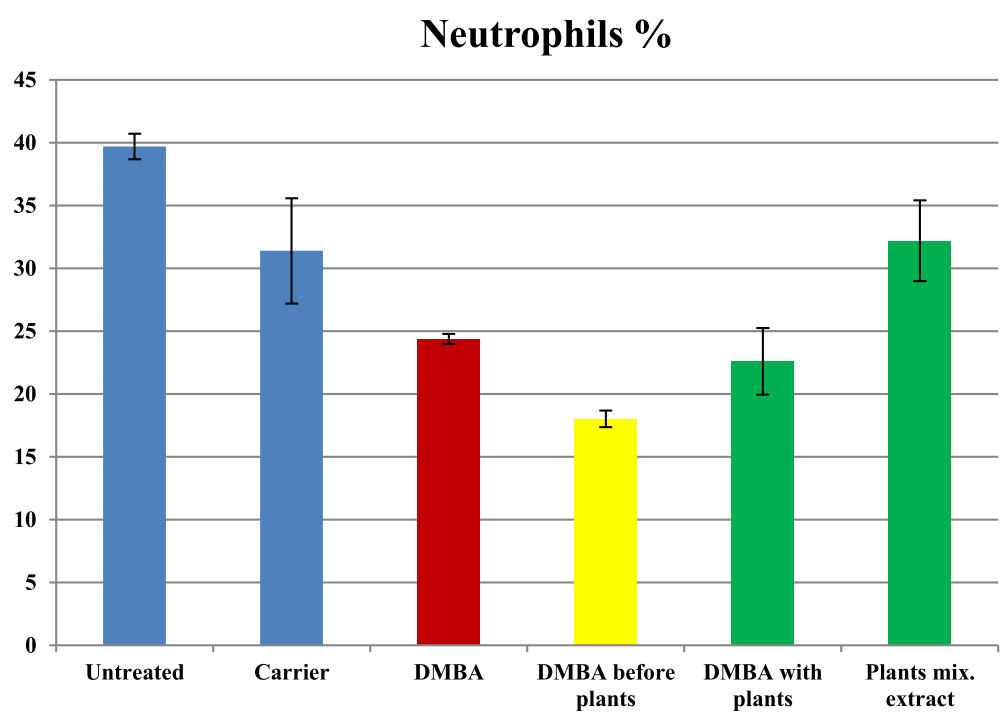

Fig. 4 Neutrophil percentage in the different rat groups. Standard errors are indicated on the bars and the significance levels are shown in Table 1

application of the plant mixture ("DMBA with plants" subgroup) compared to DMBA-treated rats without application of the plant mixture ("DMBA before plants" subgroup), confirming restoration of normal total WBC count upon treatment with the plant mixture (Figs. 1 and 2).

Compared to the "carrier" rat group, there was a significant reduction $(p<0.05)$ in lymphocyte percentage in the "DMBA before plants" rat subgroup (Fig. 3). After the application of plant mixture extract on the DMBAtreated rats, a non-significant difference $(p>0.05)$ was recorded in the lymphocyte percentage between "DMBA with plants" rat subgroup and the "carrier" rat group, indicating restoration of the normal lymphocyte count after treating rats with the plant mixture (Fig. 3). A significant decrease $(p<0.05)$ in the neutrophil percentage was recorded in the "DMBA before plants" rat subgroup compared to the "carrier" rat group (Fig. 4). After the application of plant mixture extract on the DMBA-treated rats, a non-significant difference $(p>0.05)$ in the neutrophil percentage was recorded between the "DMBA with plants" rat subgroup and the "carrier" rat group, indicating an increase in the neutrophil percentage upon treating rats with the plant mixture extract (Fig. 4). A significant increase $(p<0.05)$ in the blast percentage was recorded in the "DMBA before plants" rat subgroup compared to the "carrier" rat group (Fig. 5). After the application of plants on the DMBA-treated rats, $68 \%$ decrease in the blast percentage was recorded. These data indicate a considerable decrease in the blast percentage in the rats treated with the plant mixture extract.

\section{Blasts \%}

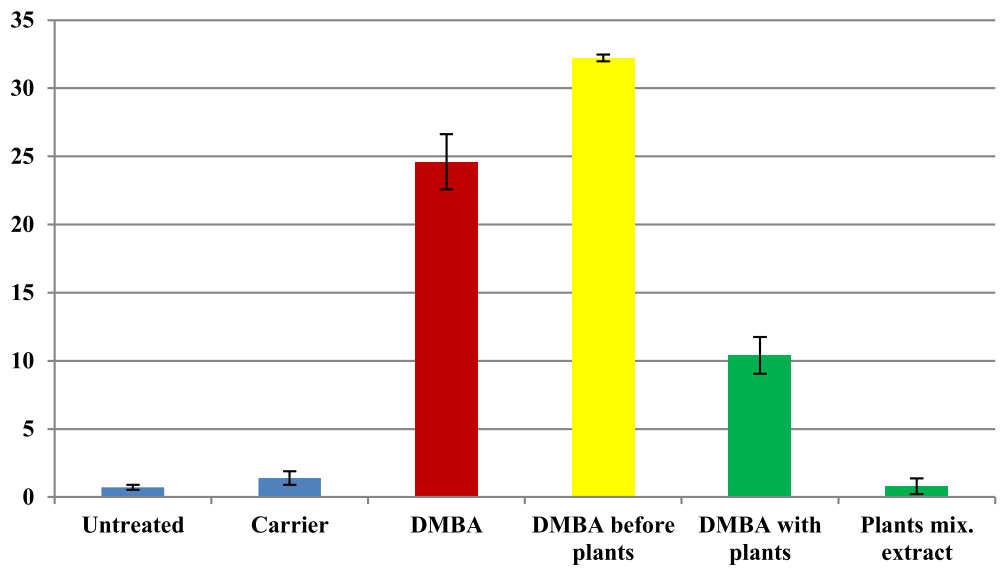

Fig. 5 Blast percentage in the different rat groups. Standard errors are indicated on the bars and the significance levels are shown in Table 1 


\section{Monocytes \%}

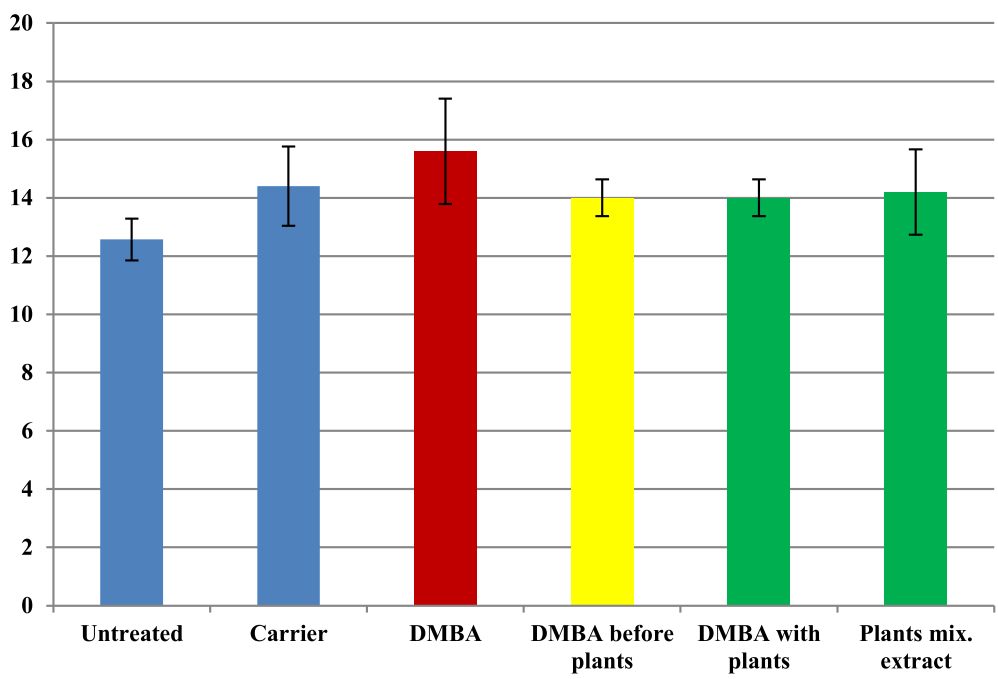

Fig. 6 Monocyte percentage in the different rat groups. Standard errors are indicated on the bars and the significance levels are shown in Table 1

Within the same group, a significant increase $(p<0.05)$ in the lymphocyte percentage was recorded in the "DMBA with plants" rat subgroup compared to "DMBA before plants" rat subgroup, indicating restoration of the normal lymphocyte count after treating rats with the plant mixture (Fig. 3). A slight but non-significant increase $(p>0.05)$ in the neutrophil percentage was recorded in the "DMBA with plants" rat subgroup compared to "DMBA before plants" rat subgroup (Fig. 4). A significant reduction $(p<0.05)$ in the blast percentage was recorded in the "DMBA with plants" rat subgroup compared to
"DMBA before plants" rat subgroup, indicating the reduction of blast number upon treating animals with plant mixture (Fig. 5). There was no significant difference in monocyte percentage $(p>0.05)$, eosinophil percentage $(p>0.05)$, or basophil percentage $(p>0.05)$ between the "carrier" rat group and the "DMBA before plants" rat subgroup (Figs. 6, 7, and 8). After application of the plant mixture on the DMBA-treated rats, there was also no significant difference in monocyte percentage $(p>0.05)$, eosinophil percentage $(p>0.05)$, or basophil percentage $(p>0.05)$ between "carrier" rat group and "DMBA with

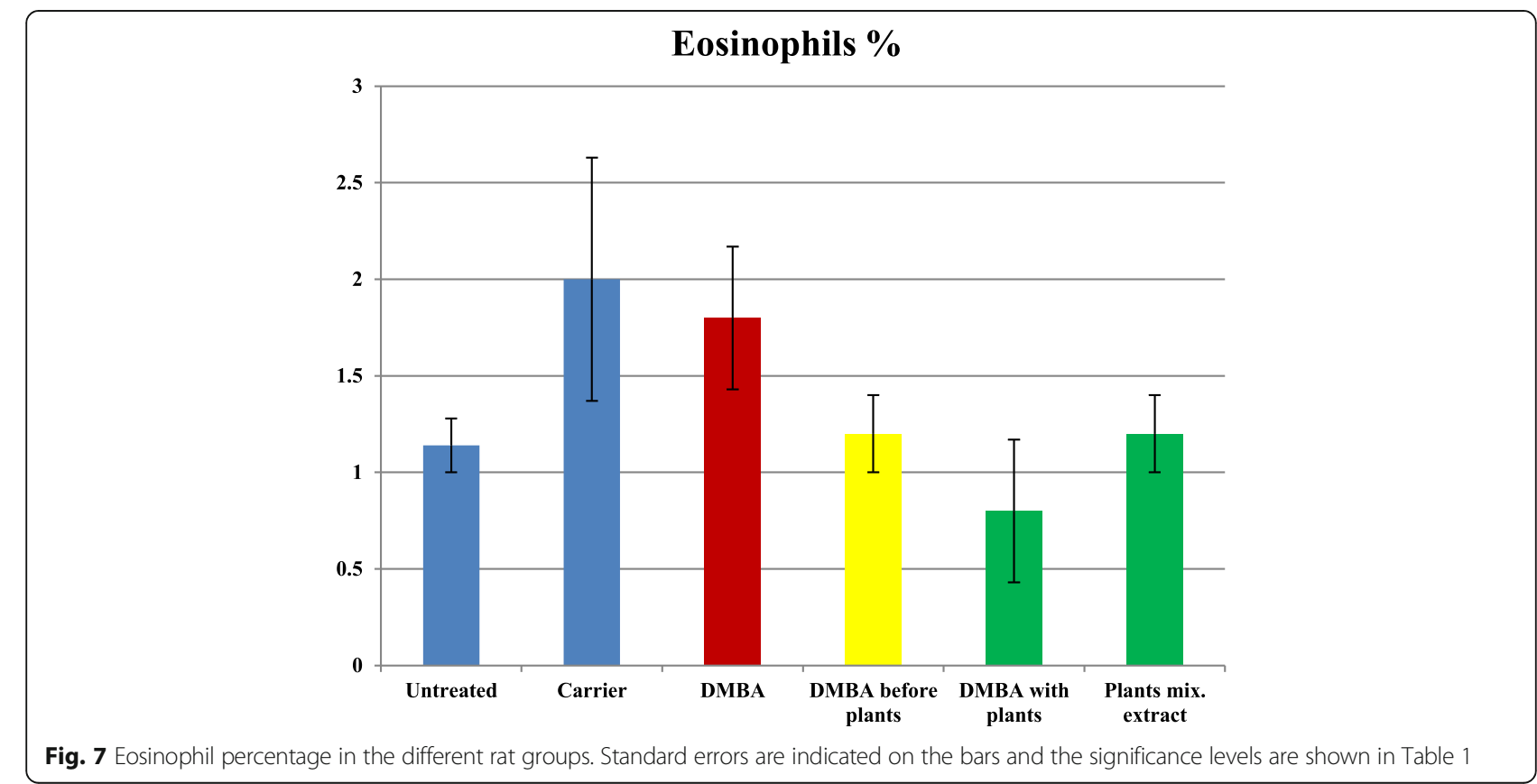


Basophils \%

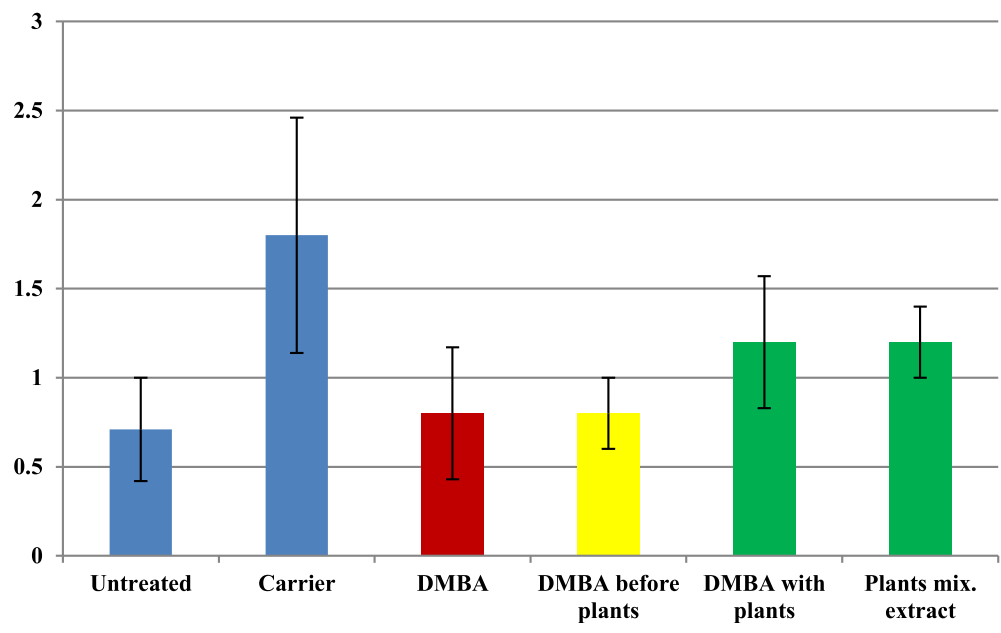

Fig. 8 Basophil percentage in the different rat groups. Standard errors are indicated on the bars and the significance levels are shown in Table 1

plants" rat subgroup (Figs. 6, 7, and 8). Within the same group, there was no significant difference in the monocyte percentage $(p>0.05)$, eosinophil percentage $(p>0.05)$, or basophil percentage $(p>0.05)$ between the "DMBA with plants" rat subgroup and the "DMBA before plants" rat subgroup (Figs. 6, 7, and 8).

\section{Effect of the plant mixture on the untreated rats}

To investigate the effect of the four-plant mixture on the untreated rats, rats were given the water extract of the four mixed plants as a drink for 2 weeks and compared with the "untreated" rat group for the biological parameters under study. There was no significant difference between the "untreated" rat group and "plant mixture" rat group in weight gain $(p>0.05)$, in total WBC count $(p>0.05)$, in lymphocyte percentage $(p>0.05)$, in neutrophil percentage $(p>0.05)$, in blast percentage $(p>0.05)$, in monocyte percentage $(p>0.05)$, in eosinophil percentage $(p>0.05)$, or in basophil percentage $(p>0.05)$ (Figs. 1, 2, 3, 4, 5, 6, 7, and 8).

\section{Sphingosine-1-phosphate receptor-1 is involved in alleviating leukemia by the plant mixture extract}

To explore whether alleviating the chemically induced leukemia by the plant mixture extract involves regulation of sphingosine-1-phosphate receptor-1 (S1PR1), lymphocytes were isolated from the "untreated," "carrier," "DMBA," "plants after DMBA," and "plant mix" rat groups and S1PR1 mRNA expression was quantitated by real-time PCR. Three rats of each group were used for this purpose. $\mathrm{Ct}$ values of S1PR1 normalized to $\beta$-actin $(\Delta \mathrm{Ct})$ are calculated and represented in Fig. 9. S1PR1 expression fold

Table 1 Significance level for the comparison of weight gain, total WBC count, and the percentage of lymphocytes, neutrophils, blasts, monocytes, eosinophils, and basophils between the different rat groups (untreated, carrier, DMBA, DMBA before plants, DMBA with plants, and plant mixture) by descriptive one-way ANOVA and Tukey's HSD analysis

\begin{tabular}{|c|c|c|c|c|c|c|c|c|c|}
\hline Group & $N$ & Weight gain & Total WBC count & Lymphocytes & Neutrophils & Blasts & Monocytes & Eosinophils & Basophils \\
\hline Untreated & 7 & 0.998 & 0.750 & 0.977 & 0.633 & 0.995 & 1.000 & 1.000 & 0.899 \\
\hline Carrier & 5 & & & & & & & & \\
\hline Carrier & 5 & 0.001 & 0.022 & 0.000 & 0.922 & 0.001 & 1.000 & 0.990 & 0.861 \\
\hline DMBA & 5 & & & & & & & & \\
\hline Carrier & 5 & 0.002 & 0.002 & 0.000 & 0.022 & 0.000 & 1.000 & 0.911 & 0.862 \\
\hline DMBA before plants & 5 & & & & & & & & \\
\hline Carrier & 5 & 1.000 & 0.999 & 0.999 & 0.490 & 0.004 & 1.000 & 0.400 & 0.999 \\
\hline DMBA with plants & 5 & & & & & & & & \\
\hline DMBA before plants & 5 & 0.003 & 0.001 & 0.004 & 0.963 & 0.000 & 1.000 & 1.000 & 1.000 \\
\hline DMBA with plants & 5 & & & & & & & & \\
\hline Untreated & 7 & 0.473 & 0.999 & 0.931 & 0.833 & 1.000 & 1.000 & 1.000 & 0.999 \\
\hline Plant mixture & 5 & & & & & & & & \\
\hline
\end{tabular}




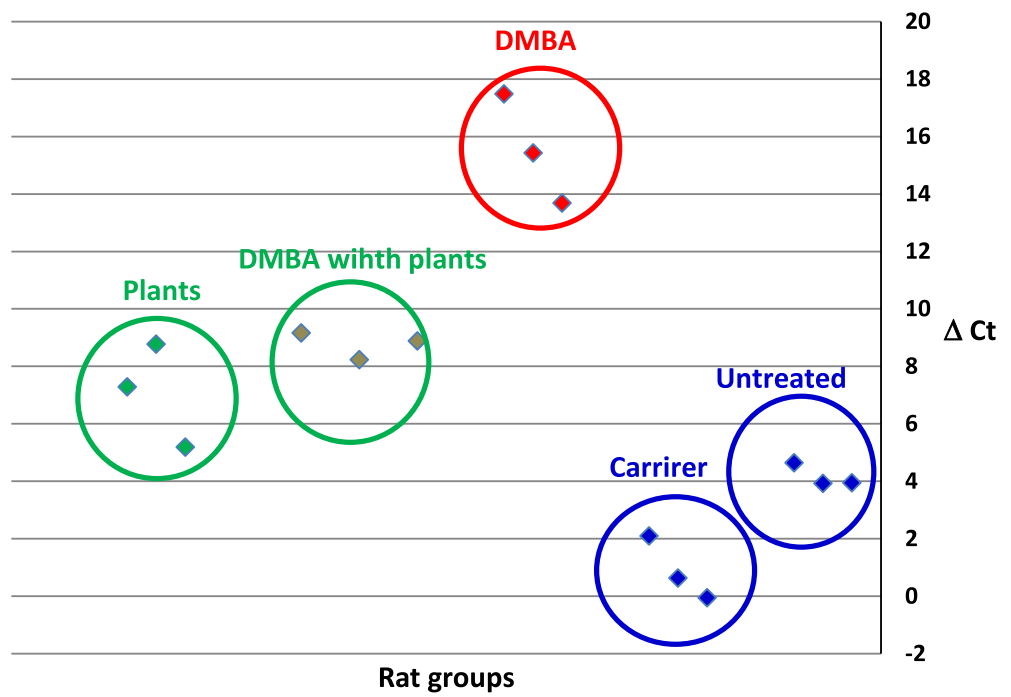

Fig. 9 Scatter plot for $\Delta C t$ of S1PR1 expression in individual rats in the five rat groups under study

change was calculated through $\Delta \Delta \mathrm{Ct}$ method and the log fold changes were represented in Fig. 10. Compared to "carrier" rat group, mRNA expression decreased by 14.6-folds in the "DMBA" rat group (Fig. 10). This decrease in S1PR1 expression was alleviated in the "plants after DMBA" rat group to 7.9-folds compared to the "carrier" rat group. Compared to the "DMBA" group, the plant mixture was able to increase S1PR1 expression by 8.5 -folds (Fig. 10).

\section{Discussion}

The data presented here show that DMBA successfully induced leukemia in rats. DMBA is known to induce leukemia disease mixed from diffuse hepatic leukemia of erythroblastic stem cells, myelogenous leukemia, lymphoblastic leukemia, and thymic leukemia (Huggins
\& Sugiyama, 1966). Treatment with DMBA has been reported to produce DMBA-DNA adducts that induce a consistent type of point mutation $\mathrm{A}$ to $\mathrm{T}$ transversion at the second base in codon 61 of the $\mathrm{N}$-ras gene (Osaka et al., 1995). This mutation is thought to arise from depurination of the DMBA-DNA adduct, followed by mis-replication across the unrepaired apurinic site (Schaaper, Kunkel, \& Loeb, 1983; Strauss, 1985). The Ras gene mutations were thought to activate multiple signaling pathways leading to cell proliferation (Maruta \& Burgess, 1994).

Results show that application of the four-plant (A. lappa, $U$. rubra, $R$. acetosella, $R$. palmatum) mixture extract successfully recovered the weight loss in the chemically induced leukemic rats. Also, this plant mixture restored the

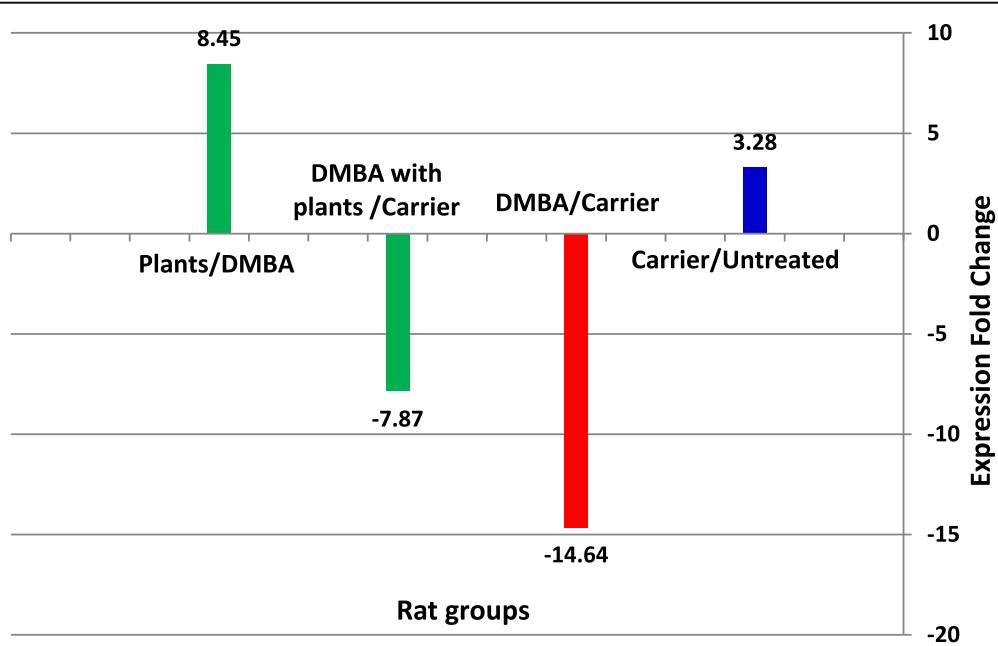

Fig. 10 Expression fold change of S1PR1 in rat groups: carrier (compared to untreated), DMBA (compared to carrier), DMBA with plants (compared to carrier), and plant mixture (compared to DMBA) 
normal total WBC count, the normal lymphocyte count, and the normal neutrophil count in the leukemic rats compared to the "carrier" rat group. Moreover, the plant mixture decreased the percentage of blasts by two thirds in the leukemic rats. These results are in agreement with previous studies demonstrating the inhibitory effects of Essiac ${ }^{\circ}$ on cancer (Tamayo et al., 2000; Tai, Cheung, Wong, \& Lowe, 2004; Leonard et al., 2006). Essiac ${ }^{\circ}$ modifies the immune response (Seely et al., 2007). Treatment of isolated human $\mathrm{T}$ cells from healthy donors with Essiac ${ }^{\circ}$ significantly stimulated CD8+ cells, in a dose-dependent manner (Seely et al., 2007). Modification of suppressed T cell function plays a significant role in cancer treatment modalities (Knutson \& Disis, 2005), and enhancement of CD8+ activity by Essiac ${ }^{\circ}$ was considered as an interesting mechanism for further investigation of the purported anticancer effects of Essiac ${ }^{\circ}$ (Seely et al., 2007). In addition, Essiac ${ }^{\circ}$ was also reported to have a greater cytotoxicity for neoplastic cells than normal cells (Ottenweller, Putt, Blumenthal, Dhawale, \& Dhawale, 2004; Tai et al., 2004).

The Essiac ${ }^{\circ}$ tea has been used in the treatment of cancer for over 80 years (Leonard et al., 2006) and it has been used as an alternative medicine by some cancer patients (Tamayo et al., 2000). Essiac ${ }^{\circ}$ is not used by breast cancer patients only but also by patients suffering from a variety of cancers (Fraser \& Allen, 1977). Essiac ${ }^{\circ}$ has been shown to inhibit cell proliferation and induce differentiation in human prostate cancer cell lines (Ottenweller et al., 2004; Tai et al., 2004).

Several reports and studies have manipulated the effect of the plants composing this mixture. A. lappa was used as a complementary therapy among breast cancer survivors (Mills, Ernst, Singh, Ross, \& Wilson, 2003) and it had antitumor effects on pancreatic cancer cell lines (Matsumoto, Hosono-Nishiyama, \& Yamada, 2006). A. lappa extract caused necrosis in solid tumors in mice (Dombrádi \& Földeák, 1965) and inhibited the effects of known mutagens (Belkin \& Fitzgerald, 1952). A. lappa root contains polyphenols and flavonoids (e.g., quercetin) that have synergistic cytotoxic effects with certain chemotherapeutic drugs, such as cisplatin (Scambia et al., 1990). A. lappa and U. rubra roots contain tannin that is an active phenolic compound (Duke, 1992; Tamayo et al., 2000; Chan et al., 2010; Ferracane, Graziani, Gallo, Fogliano, \& Ritieni, 2010) that induces macrophage responses, inhibits tumor growth, and possesses immuno-modulatory properties (Miyamoto et al., 1993). Furthermore, A. lappa contains arctigenin that is a phenyl propanoid dibenzyl butyrolactone lignan which has antioxidant, anti-inflammatory, and antitumor activities (Tamayo et al., 2000; Cho, Jang, Kim, \& Kim, 2004; Awale et al., 2006; Zhao, Wang, \& Liu, 2009). Arctigenin has been reported to inhibit the growth of leukocyte cancer cells (Matsumoto et al., 2006) and the proliferation of cancer cells by induction of apoptosis (Matsumoto et al., 2006) or by cell cycle arrest (Hausott, Greger, \& Marian, 2003; Yoo et al., 2010; Jeong, Hong, Jeong, \& Koo, 2011), nitric oxide synthase, interleukin-6 (Zhao et al., 2009), interleukin-2, interferon gamma gene expression in primary human $\mathrm{T}$ lymphocytes (Tsai et al., 2011), and TNF-a production in macrophages (Cho et al., 2004).

A. lappa root and $R$. palmatum contain relatively high concentrations of flavones, anthraquinones, tannins, and certain polysaccharides. These components have antioxidant, immunomodulatory, antimutagenic, and cytostatic effects (Kato, Ando, Tamura, \& Arima, 1971; Miyamoto et al., 1993; Yanagihara, Ito, Toge, \& Numoto, 1993; Wong, Leung, Fung, \& Choy, 1994; Liwen \& Jiazhen, 2008; Predes, Ruiz, Carvalho, Foglio, \& Dolder, 2011).

U. fulva bark has been used as a folk medicine for a wide variety of diseases (Cook, 1869; Felter and Lloyd, 1905). U. fulva bark is rich in polysaccharides (Beveridge, Stoddart, Szarek, \& Jones, 1969), tannins, and proanthocyanidins (Duke, 1992). U. rubra bark extract contains procyanidin B1, catechin, epicatechin, and procyanidin B2 (Saleem et al., 2009).

Slippery elm (U. rubra or $U$. fulva) contains high concentrations of fatty acids and fatty acid esters (Kaegi, 1998) which have cytostatic activity and immuno-modulatory effect in cell systems and in animal studies (Kato et al., 1971; Wong et al., 1994).

$R$. acetosella and $R$. palmatum contain emodin and chrysophanic acid (Tamayo et al., 2000) which are anthraquinone derivatives reported to have cytotoxic, antitumorigenic, antioxidant properties, and immunosuppressive properties (Yim et al., 1999; Zhang, Lau, Xia, Hortobagyi, \& Hung, 1999; Süleyman, Demirezer, Kuruüzüm-Uz, \& Akçay, 2002; Tzeng, Lu, Liou, Chang, \& Liu, 2012). In addition, Rumex plants contain other anthraquinones like physcion, aloe emodin, rhein, barbaloin, sennoside A, and sennoside B (Wegiera, Smolarz, Wianowska, \& Dawidowicz, 2007), and they all showed various pharmacological properties, such as antitumor (Kimura, Sumiyoshi, Taniguchi, \& Baba, 2008), antimutagenic (Lee et al., 2005), and antioxidant activities (Demirezer, Kuruüzüm-Uz, Bergere, Schiewe, \& Zeeck, 2001).

Our results showed that S1PR1 mRNA expression in lymphocytes decreased by 14.6-folds in the leukemic rats (DMBA-treated) compared to the control rat group (carrier-treated). This decrease in S1PR1 expression has been reduced to 7.9-folds in the leukemic rats after treating them with the plant mixture. In other words, compared to the leukemic rats, the plant mixture was able to increase S1PR1 expression by 8.5 -folds after treating animals with the plant mixture. 
It is worthy to mention that mRNA levels are considered as correlative with S1PR1 expression at the protein level, and in some types of cells, this correlation may not be so strong; however, for all the studies done on S1PR1 in different kinds of cells, there were no reports indicating a discrepancy between S1PR1 expression at the mRNA level and at the protein level. S1PR1 was strongly expressed on small lymphocytes forming primary lymphoid follicles and the mantle zone in secondary lymphoid follicles (Nishimura et al., 2010). S1PR1 plays a crucial role in $\mathrm{T}$ - and B-lymphocyte trafficking and drives their exit from the lymph nodes and thymus into the circulation (Cahalan et al., 2011; Borge et al., 2014). S1PR1 is thought to regulate naive lymphocyte egress from the lymph node via the lymphatic vessels by sealing the lymphatic endothelial barrier and disallowing naive $\mathrm{T}$ cell egress from lymph node and thymus (Alfonso, McHeyzer-Williams, \& Rosen, 2006; Sanna et al., 2006). Egress is a more complex process than just sensing of the ligand S1P (Cyster \& Schwab, 2012) that is present in high quantities in the lymph (Benechet et al., 2016). Once lymphocytes reach circulation, the surface expression of S1PR1 is rapidly downregulated (Lo, Xu, Proia, \& Cyster, 2005) as a result of the high amounts of S1P in the lymph and blood (Pappu et al., 2007).

S1P1 has been reported to be expressed in several hematological malignancies including expression by classical Hodgkin's lymphoma cells, B cell chronic lymphocytic leukemia, and activated B cell-like diffuse large B cell lymphoma (Capitani et al., 2012; Liu et al., 2012; Kluk et al., 2013). Expression of S1PR by blood cancer cells may directly regulate their survival by controlling the localization of cells within permissive environments such as the lymph nodes (Blaho \& Hla, 2014).

S1PR1 was found to be expressed at variable levels on leukemic cells from chronic lymphocytic leukemia patients (Capitani et al., 2012). The expression of the receptor was reduced by different signals that leukemic cells may encounter within the microenvironment of lymphoid tissues (Borge et al., 2014). It was suggested that leukemic cells may reduce the expression of S1PR1 and may delay their egress into the circulation, extending their stay at survival niches (Borge et al., 2014).

S1P has been implicated in disorders such as cancer and inflammatory diseases, and several agonists and antagonists have been developed and are in clinical trials that target S1PR1 (Kunkel et al., 2013). Examples of these drugs include Fingolimod and phosphorylated Fingolimod (S1PR1 agonist and functional antagonist) that inhibits lymphocyte trafficking and decreases colitis and cancer progression (Mandala et al., 2002; Brinkmann et al., 2010; Lee et al., 2010; Liang et al., 2013), VPC44116 (S1PR1 antagonist) that decreases Hodgkin's lymphoma (Kluk et al.,
2013), and W146 (S1PR1 antagonist) that induces lymphopenia (Tarrason et al., 2011; Sanna et al., 2006). It is possible that the plant mixture under study contains some S1PR1 agonists/antagonists that regulate S1PR1 expression and the number of lymphocytes in the DMBAtreated rats.

Up to our knowledge and except for the apoptotic effect of A. lappa on leukemic cell lines (Awale et al., 2006), no studies have investigated the effect of this plant mixture on leukemia in vivo. Our results further support the previous reports about the anti-carcinogenic effect of this plants' mixture and attract attention to its anti-leukemic activity.

\section{Conclusions}

The easy to prepare water extract of A. lappa, U. rubra, and $R$. acetosella is able to ameliorate leukemia induced experimentally in rats as evidenced in restoring the normal total WBC, lymphocyte, and neutrophil counts and the considerable decrease in the percentage of blasts. Also, this mixture alleviated the downregulation of sphingosine-1-phosphate receptor-1 associated with leukemia. The previously claimed anti-carcinogenic effect of this plant mixture is further extended by this study to the possible use in treating leukemia.

\section{Acknowledgements \\ Authors would like to thank Radwa R. El-Tahan for the help during the conducting of this study. \\ Funding \\ This study was funded in part by the Zoology Department, Faculty of Science, Damietta University, Egypt.}

\section{Availability of data and materials}

Datasets generated and analyzed during the current study are available on reasonable request to the corresponding author.

\section{Authors' contributions}

MK has done experiments and participated in writing the manuscript, AG has participated in doing the experiments, writing and revising the manuscript, and making the experimental design. SM suggested the study topic and participated in the experimental design. All authors read and approved the final manuscript.

\section{Ethics approval}

All animals used in this study were reared and treated in an ethical way as approved by our institution.

\section{Consent for publication}

Not applicable.

\section{Competing interests}

The authors declare that they have no competing interests.

\section{Publisher's Note}

Springer Nature remains neutral with regard to jurisdictional claims in published maps and institutional affiliations. 
Received: 30 May 2017 Accepted: 5 January 2018

Published online: 30 January 2018

\section{References}

Abdullah, T. H., Kandil, O., Elkadi, A., \& Carter, J. (1988). Garlic revisited: Therapeutic for the major diseases of our times. Journal of the National Medical Association., 80, 439-445.

Alenad, A. M., Al-Jaber, N. A., Krishnaswamy, S., Yakout, S. M., Al-Daghri, M. N., \& Alokail, M. S. (2013). Achillea fragrantissima extract exerts its anticancer effect via induction of differentiation, cell cycle arrest and apoptosis in chronicmyeloid leukemia (CML). Journal of Medicinal Plants Research., 7, $1561-1567$

Alfonso, C., McHeyzer-Williams, M. G., \& Rosen, H. (2006). CD69 down-modulation and inhibition of thymic egress by short- and long-term selective chemical agonism of sphingosine 1-phosphate receptors. European Journal of Immunology, 36, 149-159.

Al-Gebaly, A. S. (2017). Ameliorative effect of Arctium lappa against cadmium genotoxicity and histopathology in kidney of Wistar rat. Pakistan Journal of Biological Sciences, 20, 314-319.

Awale, S., Lu, J., Kalauni, S., Kurashima, Y., Tezuka, Y., Kadota, S., \& Esumi, H. (2006). Identification of arctigenin as an antitumor agent having the ability to eliminate the tolerance of cancer cells to nutrient starvation. Cancer Research, 66, 1751-1757

Azher, U., \& Shiggaon, N. (2013). Oral health status of children with acute lymphoblastic leukemia undergoing chemotherapy. Indian Journal of Dental Research, 24, 523

Belkin, M., \& Fitzgerald, D. B. (1952). Tumor-damaging capacity of plant materials: I. Plants used as cathartics. Journal of the National Cancer Institute, 13, 139-155.

Benechet, P. A., Menon, M., Xu, D., Samji, T., Maher, L., Murooka, T. T., ... Khanna, M. K. (2016). T cell-intrinsic S1PR1 regulates endogenous effector T-cell egress dynamics from lymph nodes during infection. PNAS, 113, 2182-2187.

Beveridge, R. J., Stoddart, J. F., Szarek, W. A., \& Jones, J. K. N. (1969). Some structural features of the mucilage from the bark of Ulmus fulva (slippery elm mucilage). Carbohydrate Research, 9, 429-439.

Blaho, V. A., \& Hla, T. (2014). An update on the biology of sphingosine 1phosphate receptors. Journal of lipid research., 55, 1596-1608.

Borge, M., Lenicov, F. R., Nannini, P. R., Alicandu, M., Enrique, P., Ceballos, A., ... Gamberale, R. (2014). The expression of Sphingosine-1 phosphate receptor-1 in chronic lymphocytic leukemia cells is impaired by tumor microenvironmental signals and enhanced by Piceatannol and R406. Journal of Immunology, 193, 3165-3174.

Bradley, P. R. (1992). Slippery elm bark, in: British herbal compendium, (vol. 1). Bournemouth: British Herbal Medicine Association.

Brinkmann, V., Billich, A., Baumruker, T., Heining, P., Schmouder, R., Francis, G., ... Burtin, P. (2010). Fingolimod (FTY720): Discovery and development of an oral drug to treat multiple sclerosis. Nature Rev. Drug Discov., 9, 883-897.

Cahalan, S. M., Gonzalez-Cabrera, P. J., Sarkisyan, G., Nguyen, N., Schaeffer, M. T., Huang, L., ... Rosen, H. (2011). Actions of a picomolar short-acting S1P1 agonist in S1P1-eGFP knock-in mice. Nature Chemical Biology, 7, 254-256.

Camp-Sorrell, D. (2000). Chemotherapy: Toxicity management. In C. H. Yarbro, M. H. Frogge, M. Goodman, \& S. L. Groenwald (Eds.), Cancer nursing: Principles and practice, (pp. 444-486). Sudbury: Jones and Bartlett Publishers.

Capitani, N., Patrussi, L., Trentin, L., Lucherini, O. M., Cannizzaro, E., Migliaccio, E., ... Baldari, T. C. (2012). S1P1 expression is controlled by the pro-oxidant activity of p66Shc and is impaired in B-CLL patients with unfavorable prognosis. Blood, 120, 4391-4399.

Castleman, M. (1991). The healing herbs: The ultimate guide to the curative power of nature's medicines. Emmaus: Rodale Press.

Chae, S. S., Proia, R. L., \& Hla, T. (2004). Constitutive expression of the S1P1 receptor in adult tissues. Prostaglandins \& Other Lipid Mediators, 73, 141-150.

Chan, Y. S., Cheng, L. N., Wu, J. H., Chan, E., Kwan, Y. W., Lee, S. M. Y., ... Chan, S. W. (2010). A review of the pharmacological effects of Arctium lappa (burdock). Inflammopharmacology, 19, 245-254.

Cho, M. K., Jang, Y. P., Kim, Y. C., \& Kim, S. G. (2004). Arctigenin, a phenylpropanoid dibenzylbutyrolactone lignan, inhibits MAP kinases and AP1 activation via potent MKK inhibition: The role in TNF-a inhibition. International Immunopharmacology, 4, 1419-1429.

Cook, W. (1869). The Physio-medical dispensatory: A treatise on therapeutics. In Materia Medica, and pharmacy in accordance with the principles of physiological medication. Cincinnati: WM. H. Cook.
Cyster, J. G., \& Schwab, S. R. (2012). Sphingosine-1-phosphate and lymphocyte egress from lymphoid organs. Annual Review of Immunology, 30, 69-94.

De Almeida, A. B., Luiz-Ferreira, A., Cola, M., Di Pietro Magri, L., Batista, L. M., de Paiva, J. A., ... Souza-Brito, A. R. (2012). Anti-ulcerogenic mechanisms of the sesquiterpene lactone onopordopicrin- enriched fraction from Arctium lappa L. (Asteraceae): Role of somatostatin, gastrin, and endogenous sulfhydryls and nitric oxide. Journal of Medicinal Food., 15, 378-383.

De Lima, A. R., Noris-Suárez, K., Bretaña, A., Contreras, V. T., Navarro, M. C., PérezYbarra, L., \& Bubis, J. (2017). Growth arrest and morphological changes triggered by emodin on Trypanosoma cruzi epimastigotes cultivated in axenic medium. Biochimie, 142, 31-40.

Demirezer, L. O., Kuruüzüm-Uz, A., Bergere, I., Schiewe, H. J., \& Zeeck, A. (2001). The structures of antioxidant and cytotoxic agents from natural source: Anthraquinones and tannins from roots of Rumex Patientia. Phytochemistry, $58,1213-1217$

Dombrádi, C. A., \& Földeák, S. (1965). Screening report on the antitumor activity of purified Arctium lappa extracts. Tumori, 52, 173-175.

Duh, P. (1998). Antioxidant activity of burdock (Arctium lappa Linne): Its scavenging effect on free-radical and active oxygen. Journal of the American Oil Chemists' Society, 75, 455-461.

Duke, J. A. (1992). Handbook of biologically active Phytochemicals and their activities. Boca Raton: CRC Press.

Duke, J. A. (1997). Green pharmacy. Emmaus: Rodale Press.

Eden, T. (2010). Aetiology of childhood leukaemia. Cancer Treatment Reviews, 36, 286-297.

Felter, H. W., \& Lloyd, J. U. (1905). King's American dispensatory, (18th ed., ). Cincinnati: The Ohio Valley company.

Ferracane, R., Graziani, G., Gallo, M., Fogliano, V., \& Ritieni, A. (2010). Metabolic profile of the bioactive compounds of burdock (Arctium Lappa) seeds, roots and leaves. Journal of Pharmaceutical and Biomedical Analysis, 51, 399-404.

Fraser, S. S., \& Allen, C. (1977). Could Essiac halt cancer, (pp. 12-14). Homemaker's Magazine.

Gescher, K., Hensel, A., Hafezi, W., Derksen, A., \& Kühn, J. (2011). Oligomeric proanthocyanidins from Rumex Acetosa $\mathrm{L}$. inhibit the attachment of herpes simplex virus type-1. Antiviral Research, 89, 9-18.

Hausott, B., Greger, H., \& Marian, B. (2003). Naturally occurring lignans efficiently induce apoptosis in colorectal tumor cells. Journal of Cancer Research and Clinical Oncology, 129, 569-576.

Huggins, C. B., \& Sugiyama, T. (1966). Induction of leukemia in rat by pulse doses of 7,12-dimethylbenz(a)anthracene. Pathology, 55, 74-81.

Javed, F., Utreja, A., Correa, F. O. B., Al-Askar, M., Hudieb, M., Qayyum, F., .. AlHezaimi, K. (2012). Oral health status in children with acute lymphoblastic leukemia. Critical reviews in oncology/hematology., 83, 303-309.

Jeong, J. B., Hong, S. C., Jeong, H. J., \& Koo, J. S. (2011). Arctigenin induces cell cycle arrest by blocking the phosphorylation of $\mathrm{Rb}$ via the modulation of cell cycle regulatory proteins in human gastric cancer cells. International Immunopharmacology, 11, 1573-1577.

Kaegi, E. (1998). Unconventional therapies for cancer. 1. Essiac. CMAJ, 158, 897-902.

Kato, A., Ando, K., Tamura, G., \& Arima, K. (1971). Effects of some fatty acid esters on the viability and transplantability of Ehrlich ascites tumor cells. Cancer Research, 31, 501-504.

Kimura, Y., Sumiyoshi, M., Taniguchi, M., \& Baba, K. (2008). Antitumor and antimetastatic actions of anthrone-C-glucoside, cassialoin isolated from Cassia garrettiana heartwood in colon 26-bearing mice. Cancer Science, 99, 2336-2348.

Kinane, D. (1999). Blood and lymphoreticular disorders. Periodontology 2000, 21, 84-93.

Kluk, M. J., Ryan, K. P., Wang, B., Zhang, G., Rodig, S. J., \& Sanchez, T. (2013). Sphingosine-1-phosphate receptor 1 in classical Hodgkin lymphoma: Assessment of expression and role in cell migration. Laboratory Investigation, 93, 462-471.

Knutson, K. L., \& Disis, M. L. (2005). Tumor antigen-specific Thelper cells in cancer immunity and immunotherapy. Cancer Immunology, Immunotherapy, 54, 721-728.

Kulp, K. S., Montgomery, J. L., Nelson, D. O., Cutter, B., Latham, E. R., Shattuck, D. L. ,... Bennett, L. M. (2006). Essiac_ and flor-Essence_ herbal tonics stimulate the in vitro growth of human breast cancer cells. Breast Cancer Research and Treatment., 98, 249-259.

Kunkel, G. T., Maceyka, M., Milstien, S., \& Spiegel, S. (2013). Targeting the sphingosine1-phosphate axis in cancer, inflammation and beyond. Nature Reviews. Drug Discovery, 12, 688-702. https://doi.org/10.1038/nrd4099.

Kupchan, S. M., \& Karim, A. (1977). Tumor inhibitors: 114. Aloe emodin: Antileukemic principle isolated from Rhamnus frangula L. Lloydia, 39, 223-224. 
Lee, H., Lee, H., Deng, J., Kujawski, M., Yang, C., Liu, Y., .. Yu, H. (2010). STAT3induced S1PR1 expression is crucial for persistent STAT3 activation in tumors. Nature Med., 16, 1421-1428.

Lee, N. J., Choi, J. H., Koo, B. S., Ryu, S. Y., Han, Y. H., Lee, S. I., \& Lee, D. U. (2005). Antimutagenicity and cytotoxicity of the constituents from the aerial parts of Rumex acetosa. Biological \& Pharmaceutical Bulletin, 28, 2158-2161.

Leonard, S. S., Keil, D., Mehlman, T., Proper, S., Shi, X., \& Harris, G. K. (2006). Essiac tea: Scavenging of reactive oxygen species and effects on DNA damage. Journal of Ethnopharmacology, 103, 288-296.

Liang, J., Nagahashi, M., Kim, E. Y., Harikumar, K. B., Yamada, A., Huang, W., .. Spiegel, S. (2013). Sphingosine-1-phosphate links persistent STAT3 activation, chronic intestinal inflammation, and development of colitis-associated cancer. Cancer Cell, 23, 107-120.

Lin, C., Lin, J., Yang, J., Chuang, S., \& Ujiie, T. (1996). Anti-inflammatory and radical scavenge effects of Arctium lappa. The American Journal of Chinese Medicine, 24, 127-137.

Lin, S., Lin, C., Lin, C., Lin, Y., Chen, C., Chen, I., \& Wang, L. (2002). Hepatoprotective effects of Arctium lappa linne on liver injuries induced by chronic ethanol consumption and potentiated by carbon tetrachloride. Journal of Biomedical Science, 9, 401-409.

Liu, Y., Deng, J., Wang, L., Lee, H., Armstrong, B., Scuto, A., .. Yu, H. (2012). S1PR1 is an effective target to block STAT3 signaling in activated B cell-like diffuse large B-cell lymphoma. Blood, 120, 1458-1465.

Liwen, W., \& Jiazhen, P. (2008). Extraction process of micro-injection of supercritical fl uid under hyper high pressure of inulin from Arctium Lappa. Shipin Yu Shengwu Jishu Xuebao., 27, 61-64.

Lo, C. G., Xu, Y., Proia, R. L., \& Cyster, J. G. (2005). Cyclical modulation of sphingosine-1-phosphate receptor 1 surface expression during lymphocyte recirculation and relationship to lymphoid organ transit. The Journal of Experimental Medicine, 201, 291-301.

Love, A. A. (1936). Manifestations of leukemia encountered in otolaryngology and stomatologic practices. Archives of Otolaryngology, 23, 173-221.

Mandala, S., Hajdu, R., Bergstrom, J., Quackenbush, E., Xie, J., Milligan, J., ... Rosen, H. (2002). Alteration of lymphocyte trafficking by sphingosine-1-phosphate receptor agonists. Science, 296, 346-349.

Mankaran, S., Dinesh, K., Deepak, S., \& Gurmeet, S. (2013). Typhonium falgelliforme: A multipurpose plant. Int Res J Pharm., 4, 45-48.

Maruta, H., \& Burgess, A. W. (1994). Regulation of the Ras signaling supported by the Deutsche Forschungsgemeinschaft. BioEssays, 16, 489-496.

Masuda, T., \& Ueno, Y. (1984). Microsomal transformation of emodin into a direct mutagen. Mutation Research, 125, 135-144.

Matsumoto, T., Hosono-Nishiyama, K., \& Yamada, H. (2006). Antiproliferative and apoptotic effects of butyrolactone lignans from Arctium Lappa on leukemic cells. Planta medica., 72, 276-278.

Mills, E., Ernst, E., Singh, R., Ross, C., \& Wilson, K. (2003). Health food store recommendations: Implications for breast cancer patients. Breast Cancer Research, 5, 170-174.

Minyi, C. (1992). Anticancer medicinal herbs. Hunan: Hunan Science and Technology Publishing House.

Miyamoto, K., Nomura, M., Sasakura, M., Matsui, E., Koshiura, R., Murayama, T., .. Okuda, T. (1993). Antitumor activity of oenothein B, a unique macrocyclic ellagitannin. Japanese Journal of Cancer Research, 84, 99-103.

Morita, H., Umeda, M., Masuda, T., \& Ueno, Y. (1988). Cytotoxic and mutagenic effects of emodin on cultured mouse carcinoma FM3A cells. Mutation Research, 204, 329-332.

Nishimura, H., Akiyama, T., Monobe, Y., Matsubara, K., Igarashi, Y., Abe, M., ... Sadahira, Y. (2010). Expression of sphingosine-1-phosphate receptor 1 in mantle cell lymphoma. Modern Pathology., 23, 439-449.

Osaka, M., Matsuo, S., Koh, T., Liang, P., Kinoshita, H., Maeda, S., \& Sugiyama, T. (1995). N-ras mutation in 7,12-dimethylbenz[a]anthracene (DMBA)-induced erythroleukemia in long-Evans rats. Cancer Letters, 91, 25-31.

Ottenweller, J., Putt, K., Blumenthal, E. J., Dhawale, S., \& Dhawale, S. W. (2004). Inhibition of prostate cancer-cell proliferation by Essiac. Journal of Alternative and Complementary Medicine., 10, 687-691.

Pappu, R., Schwab, S. R., Cornelissen, I., Pereira, J. P., Regard, J. B., Xu, Y., ... Coughlin, S. R. (2007). Promotion of lymphocyte egress into blood and lymph by distinct sources of sphingosine-1- phosphate. Science, 316, 295-298.

Predes, F. S., Ruiz, A. L., Carvalho, J. E., Foglio, M. A., \& Dolder, H. (2011). Antioxidative and invitro antiproliferative activity of Arctium Lappa root extracts. BMC Complementary and Alternative Medicine., 11, 1-5.
Quinn, M., Babb, P., Brock, A., Kirby, L., \& Jones, J. (2001). Cancer trends in England and Wales 1950-1999. London: Office for National Statistics.

Rivera, R., \& Chun, J. (2006). Biological effects of lysophospholipids. Reviews of Physiology, Biochemistry and Pharmacology, 160, 25-46.

Saleem, A., Walshe-Roussel, B., Harris, C., Asim, M., Tamayo, C., Sit, S., \& Arnason, T. T. (2009). Characterisation of Phenolics in flor- essence $-A$ compound herbal product and its contributing herbs. Phytochemical Analysis, 20, 395-401.

Sanna, M. G., Wang, S. K., Gonzalez-Cabrera, P. J., Don, A., Marsolais, D., Matheu, M. P., \& Cahalan, M. D. (2006). Enhancement of capillary leakage and restoration of lymphocyte egress by a chiral S1P1 antagonist in vivo. Nature chemical biology., 2, 434-441.

Scambia, G., Ranelletti, F. O., Panici, P. B., Bonanno, G., De Vincenzo, R., Piantelli, M. , \& Mancuso, S. (1990). Synergistic antiproliferative activity of quercetin and cisplatin on ovarian cancer cell growth. Anti-Cancer Drugs, 1, 45-48.

Schaaper, R. M., Kunkel, T. A., \& Loeb, L. A. (1983). Infidelity of DNA synthesis associated with bypass of apurinic sites. Proceedings of the National Academy of Sciences, 80, 487-491.

Seely, D., Kenney, D. A., Myers, S. P., Cheras, P. A., Lin, D., Li, R., ... Leonard, B. J. (2007). In vitro analysis of the herbal compound Essiac. Anticancer Research, 27, 3875-3881.

Seibel, N. L. (2008). Treatment of acute lymphoblastic leukemia in children and adolescents: Peaks and pitfalls. Hematology. American Society of Hematology. Education Program, 1, 374-380.

Soh, E. H., Jang, S. A., Joo, H., Park, S., Kang, S. C., Lee, C. H., \& Kim, S. Y. (2011). Anti- allergic and anti-inflammatory effects of butanol extract from Arctium Lappa L. Clinical and Molecular Allergy., 9, 1-11.

Strauss, B. S. (1985). Cellular aspects of DNA repair. Advances in Cancer Research, $45,45-105$.

Süleyman, H., Demirezer, L. O., Kuruüzüm-Uz, A., \& Akçay, F. (2002). Gastroprotective and antiulcerogenic effects of Rumex patientia L. extract. Die Pharmazie, 57, 204-205.

Tai, J., Cheung, S., Wong, S., \& Lowe, C. (2004). In vitro comparison of Essiac and flor-essence on human tumor cell lines. Oncology Reports, 11, 471-476.

Tamayo, C., Richardson, M. A., Diamond, S., \& Skoda, I. (2000). The chemistry and biological activity of herbs used in flor-EssenceTM herbal tonic and EssiacTM. Phytotherapy Research, 14, 1-14.

Tarrason, G., Aulí, M., Mustafa, S., Dolgachev, V., Domènech, M. T., Prats, N., ... Godessart, N. (2011). The sphingosine-1-phosphate receptor-1 antagonist, W146, causes early and short-lasting peripheral blood lymphopenia in mice. International Immunopharmacology, 11, 1773-1779.

Tsai, W. J., Chang, C. T., Wang, G. J., Lee, T. H., Chang, S. F., Lu, S. C., \& Kuo, Y. C. (2011). Arctigenin from Arctium lappa inhibits interleukin-2 and interferon gene expression in primary human T lymphocytes. Chinese Medicine., 6, 1-8.

Tzeng, T. F., Lu, H. J., Liou, S. S., Chang, C. J., \& Liu, I. M. (2012). Emodin protects against high-fat diet-induced obesity via regulation of AMP-activated protein kinase pathways in white adipose tissue. Planta Medica, 78, 943-950.

Wegiera, M., Smolarz, H. D., Wianowska, D., \& Dawidowicz, A. L. (2007). Anthracene derivatives in some species of Rumex L. genus. Acta Soc Botan., 76, 103-108.

Wong, C. K., Leung, K. N., Fung, K. P., \& Choy, Y. M. (1994). Immunomodulatory and antitumour polysaccharides from medicinal plants. The Journal of International Medical Research, 22, 299-312.

Yanagihara, K., Ito, A., Toge, T., \& Numoto, M. (1993). Antiproliferative effects of isoflavones on human cancer cell lines established from the gastrointestinal tract. Cancer Research, 53, 5815-5821.

Yim, H., Lee, Y. H., Lee, C. H., \& Lee, S. K. (1999). Emodin, an anthraquinone derivative isolated from the rhizomes of Rheum palmatum, selectively inhibits the activity of casein kinase II as a competitive inhibitor. Planta Medica., 65, 9-13.

Yoo, J. H., Lee, H. J., Kang, K., Jho, E. H., Kim, C. Y., Baturen, D., ... Nho, C. W. (2010). Lignans inhibit cell growth via regulation of Wnt/b-catenin signaling. Food and Chemical Toxicology, 48, 2247-2252.

Zhang, L., Lau, Y. K., Xia, W., Hortobagyi, G. N., \& Hung, M. C. (1999). Tyrosine kinase inhibitor emodin suppresses growth of HER-2/neu-overexpressing breast cancer cells in athymic mice and sensitizes these cells to the inhibitory effect of paclitaxel. Clinical Cancer Research, 5, 343-353.

Zhao, F., Wang, L., \& Liu, K. (2009). In vitro anti-inflammatory effects of arctigenin, a lignan from Arctium lappa L., through inhibition on iNOS pathway. Journal of Ethnopharmacology, 122, 457-462. 